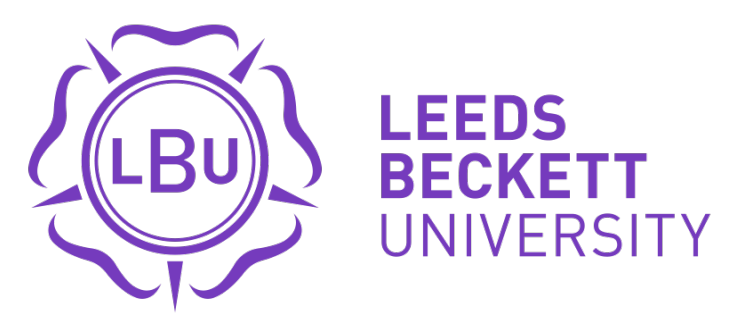

Citation:

Milligan, J (2014) Superhuman? Perceptions of accelerated students and graduates working in health care. Nurse Education Today, 34 (5). 749 - 753. DOI: https://doi.org/10.1016/j.nedt.2013.08.001

Link to Leeds Beckett Repository record:

https://eprints.leedsbeckett.ac.uk/id/eprint/227/

Document Version:

Article (Accepted Version)

The aim of the Leeds Beckett Repository is to provide open access to our research, as required by funder policies and permitted by publishers and copyright law.

The Leeds Beckett repository holds a wide range of publications, each of which has been checked for copyright and the relevant embargo period has been applied by the Research Services team.

We operate on a standard take-down policy. If you are the author or publisher of an output and you would like it removed from the repository, please contact us and we will investigate on a case-by-case basis.

Each thesis in the repository has been cleared where necessary by the author for third party copyright. If you would like a thesis to be removed from the repository or believe there is an issue with copyright, please contact us on openaccess@leedsbeckett.ac.uk and we will investigate on a case-by-case basis. 


\title{
SUPER-HUMAN? PERCEPTIONS OF ACCELERATED STUDENTS AND GRADUATES WORKING IN HEALTH CARE
}

James Milligan, Senior Lecturer

Faculty of Health \& Social Sciences

Leeds Metropolitan University

Leeds

LS1 3HE

United Kingdom

tel: +441138123494

fax: +441138123440

Email address: j.g.milligan@leedsmet.ac.uk

Key words: Accelerated education; physiotherapy; pre-registration; second-degree

\begin{abstract}
Background: Accelerated university courses were developed in response to consumer demand and educational advances yet a lack of research exists related to the impact of accelerated healthcare courses in the United Kingdom.
\end{abstract}

Objectives: This study explored clinicians' perceptions of accelerated pre-registration courses in physiotherapy.

Method: Senior clinicians were recruited by purposive sampling from several National Health Service hospitals across North-East England. Data from face-to-face semi-structured interviews was recorded, transcribed verbatim and analysed using Interpretive Phenomenological Analysis.

Findings: Findings from fourteen participants indicated their admiration of accelerated students' attributes to complete what they considered to be an intense and in-depth course. Such graduates were described as 'superhuman'. Participants' noted that accelerated graduates were likely to 'hit the ground running' in clinical settings. However, concerns were raised that some accelerated graduates' over-confidence affected team dynamics and/or affected some aspects of clinical reasoning.

Conclusions: Participants valued the varied routes to graduation whilst recognising their strengths and limitations. Findings from the study suggested the need for different types of clinical supervision to support each route.

Key words: Accelerated education; physiotherapy; pre-registration; second-degree 


\section{INTRODUCTION}

\section{Background}

The term 'accelerated education' is used to mean those training courses that are shorter in duration than traditional routes but without significant loss in content (Grounds, 1996). Such courses are also described as 'intensive', 'time compressed' or 'second degrees' as a previous university degree is a common pre-requisite (American Association of Colleges of Nursing, 2009; Scott, 2003; Husson and Kennedy, 2003). The 'adult learner' of these courses integrates their prior learning and abilities to complete studies in the shorter time (Kasworm, 2003). In the United Kingdom (UK) accelerated pre-registration courses in nursing and the allied health professions can last two years instead of the traditional three. Usually these are presented at Masters level.

Accelerated courses in nursing were created in response to consumer demand (American Association of Colleges of Nursing, 2005; Traub, 1997) and to enable more rapid entry into the workforce and so facilitate widening participation (Cangelosi and Whitt, 2005). The first accelerated pre-registration course in nursing was delivered in the United States (US) in 1971 and in Australia, Canada and the UK in the mid-1990s (Neill, 2012; Halkett and McLafferty, 2006; Cangelosi and Whitt, 2005). Within the UK accelerated pre-registration courses in physiotherapy started in 1995 (Glasgow Caledonian University, 2004), in occupational therapy in 1996 (Wilcock, 2002) and medicine in 2001 (Blythe, 2001). To date the majority of reviews of accelerated courses in health-care focus predominantly upon American studies of nursing courses. The few studies relating to accelerated courses in health-care in Australia and the UK relate to student experiences (Neill, 2011; Halkett and McLafferty, 2006; Craik, and Nappthine, 2001). Whilst one US study explored nurse managers' perceptions of accelerated graduates' abilities to work in the clinical environment (Oermann et al., 2010) no such study has explored clinicians' perceptions within other disciplines. The purpose of this paper is to discuss empirical research into the impact of 
accelerated pre-registration education in physiotherapy. Findings are compared to accelerated courses from other disciplines for wider discussion.

The literature describes many benefits to accelerated courses. An early evaluation of accelerated courses in nursing in the US described them as an efficient and effective strategy for increasing the supply of nurses by successfully recruiting a heretofore untapped pool of candidates for the profession' (Wu and Connelly, 1992, p39). It is argued that patient care can be enhanced by accelerated graduates because of their additional life-skills (American Association of Colleges of Nursing, 2005, Chartered Society of Physiotherapy, 2003). Studies from Australia, Canada and the US indicate that accelerated nursing graduates are well prepared for practice (Neill, 2012; Ouellet et al., 2008; Miklancie and Davis 2005). Academically, accelerated cohorts have proven study skills with a wealth of knowledge, experience and energy (Cangelosi and Whitt, 2005; Miklancie and Davis 2005). Such graduates of accelerated programs are "prized by nurse employers... bringing many layers of skill to the workplace being motivated and enthusiastic students who do well in the academic and clinical setting' (American Association of Colleges of Nursing, 2005, no page).

However, perceived disadvantages exist. A literature review of nine US and two Australian studies of accelerated courses in nursing concluded that students could encounter 'intense emotions, such as anxiety due to high workloads and the accelerated pace', (Neill, 2012, p90). A quote from one such study of 53 US-based accelerated baccalaureate nursing students indicated that 'nothing prepared me for this program. I had no idea how hard it would be' (Meyer et al. 2006, p326). Furthermore, participants described 'the insanity of the work- very intense, no relief' (Meyer et al., 2006, p326). Other studies describe significant detractors to be competing domestic pressures and greater financial constraints due to lack of time for additional employment (Seldomridge and DiBartolo, 2005; Youssef and Goodrich, 1996). Indeed, within a UK-based occupational therapy course $30 \%$ of the sixty-four students stated that they specifically chose traditional routes in preference to the accelerated 
route. This was because they perceived the latter to be more intensive that would not allow for additional part-time work (Craik and Nappthine, 2001).

Other shortcomings relate to perceptions of the very nature of the course. Traub referred to negative connotations of accelerated fast-track courses calling them a 'McEducation' or 'drive-thru-University' (Traub, 1997, p114). This disparaging analogy with fast food restaurants infers that accelerated courses are product orientated. This suggests a less worthy educational outcome than a journey of academic discovery. Swenson (2003) considered the term accelerated learning to be unfortunate as, by its nature, it suggests that traditional methods are normal with any deviation likely to be treated with suspicion. This view was supported by Halkett and McLafferty (2006) in Scotland who noted antagonism from traditional nursing students towards their accelerated counterparts who were made to feel inferior, treated in a derogatory manner and with animosity. Those traditionally trained nurses believed that it was not possible to complete the nursing training in less than three years. As such, accelerated students were perceived as 'cheating' or 'getting an easy ride' (Halkett and McLafferty, 2006, p164).

Some students of US- based accelerated management courses were selective in their learning to keep up with the time-compressed demands of the program relying upon their instructors to guide them in what to learn and to what depth (Kasworm, 2003). Cangelosi (2007) agreed that some American accelerated nursing students had 'little patience' for learning information what they did not view as important to become a nurse. Instead there was a desire to 'clear the way for them' to learn what they 'really need to know' (Cangelosi, 2007, p95). This resonates with Scott (2003) who questioned the accelerated learner's beliefs that they were true thinkers when they appeared to be so dependent upon their tutors. It can also question how a newcomer might know what is relevant to their future career and what is not. 
Perceptions of accelerated pre-registration courses have significance. Success of the accelerated pre-registration courses will be tempered by such perceptions and remains worthy of further exploration as their wider adoption could be resisted whilst this perception is unchallenged. Hence this study sought perceptions of clinicians who had experience of working with graduates of accelerated pre-registration courses. Physiotherapy courses were explored being JM's clinical background.

\section{METHOD}

\section{Design}

A qualitative approach was adopted. Individual semi-structured face-to-face interviews were undertaken and data analysed using Interpretative Phenomenological Analysis (IPA). IPA is a version of the phenomenological method that recognises that it is the researcher's interpretation of what is said and what arises in the analysis to create an understanding for the researcher and for others (Smith et al. 2009).

\section{Settings and subjects}

A purposive sample of participants was sought from seven National Health Service (NHS) organisations within the North-East of England who gave permissions for the research to take place in their hospital settings. Inclusion criteria were graduate physiotherapists working in the public or private sector who had undergone physiotherapy training within the UK and had experience of working with physiotherapists trained via the accelerated and traditional routes. Those physiotherapists who were not working or were potential participants but had not been granted permission by relevant line-managers were excluded.

\section{Data collection and analysis}


Having gained permissions from line managers invitations were sent to senior clinicians to volunteer to be interviewed individually within their workplaces. Data collection and analysis took place over a nine month period until saturation of data was confirmed. The semistructured face interviews sought insight into clinician's own experiences and perceptions of accelerated graduates and traditional graduates in the clinical working environment. Interviews were recorded by voice-recorder, transcribed verbatim using pseudonyms for anonymity and analysed using Interpretative Phenomenological Analysis (IPA).

\section{Ethical considerations}

Ethical permission was granted from the UK-based National Research Ethics Service (NRES) and from each of the health-care organisations in which the data collection took place. Written consent was gained from all participants and they were assured of their right to withdraw from the study at any time. Pseudonyms were used to respect participants' anonymity and raw data was held securely.

\section{FINDINGS}

Fourteen clinicians from the seven organisations were interviewed. Participants discussed graduates from accelerated and traditional courses from a number of different UK-based universities. The latter makes findings more transferable. Participants valued physiotherapists who graduated from both routes but for different reasons. From ninety codes two superordinate themes arose from the overall analysis: 'perceptions of success' and 'notes of caution'. Four key themes are presented here:

- Perceptions of success: Super-human

- Perceptions of success: Hit the ground running

- A note of caution: Comfort zone; can't see the wood for the trees

- A note of caution: Over-confidence; loose cannon 


\section{Perceptions of success: Super-human}

Participants described accelerated graduates as 'a different calibre of people', 'super people' or 'super-intelligent'... to be able to learn, comprehend, assimilate and implement all that they considered was necessary to learn in two years instead of three. The majority of participants commented upon the students' and graduates' motivation and hard work to cope with the demands of the course. Clinicians associated accelerated students' success with having to 'knuckle down and, and have to just study all the time' and to do 'more off their own back' (Participant 1). Conversely participants viewed many traditionally trained students and graduates as being less self-reliant who 'seem[ed] to, to want the information given to them erm, a lot of the time' (Participant 14). This was in contrast to

the MSc students [who] are more willing to, to go out and, and find that information for them, for themselves erm, and ask you for it rather than just sort of expecting it to come to them (Participant 14).

This general impression created a common theme indicating that traditionally trained students preferred to be 'spoon fed'. The term was used by numerous participants to mean needing guidance; to need information being given to them; to be less able to think for themselves' and to have less 'initiative'.

However participants appeared unsure of the format and philosophy of accelerated courses in the UK. Some participants questioned whether courses had been significantly altered in content. Whilst some study participants believed that the accelerated physiotherapy course was simply compressed with 'a lot more packed in'... 'into a much tighter timescale' (Participant 11) others assumed that elements must have been cut. For others there was a perception of reduced depth of knowledge, understanding and application in that 'I don't think it's [the basics are] covered in perhaps as much detail' (Participant 14). Whilst UKbased academics realise that all vocational courses are scrutinised by the relevant statutory bodies (Nursing and Midwifery Council, 2010; Health Professions Council, 2007) clinicians appeared to find shortened courses to be confusing. Indeed one senior clinician worried that 
something was 'niggling' at the back of her mind despite the fact that the accelerated graduates had 'already proved themselves'...:

... so I should not have that in the back of my head ...erm, that, that they might have missed something ...

[JM: What might they have missed?]

... something they might have not learned that they needed to learn which is kind of ridiculous because if they had they wouldn't have got through their exams and their clinical placements.

[JM: So what is niggling at the back of your mind?]

...I wonder if it's like ... it took me three years to learn this stuff, what makes them think they can do it in two?

(Participant 1).

Hence there appeared to be an inconsistency between participants' compliments towards accelerated graduates' academic success and concerns of the credibility of the courses.

\section{Perceptions of success: Hit the ground running}

Many participants applauded accelerated graduates' attributes that enabled them to 'hit the ground running' in the clinical environment. They said:

they come on the ward, you show 'em round and they're ready to work, they don't they don't ask if they can watch you for, a day to learn the ropes, you show them the paperwork and they just get on with it (Participant 1).

Indeed, participants spoke of accelerated graduates' age, experience and maturity enabling a confident disposition and hence greater communication skills. They were impressed with the accelerated graduates' abilities to work in complex and busy workplaces. They associated the accelerated graduates' excellent communication skills with greater selfconfidence. Such graduates were said to 'rapidly' fit into the busy and complex multidisciplinary team and were more able to successfully negotiate their therapeutic input into the busy ward schedule. The accelerated graduate:

would've gone in- and just sort of watched and then come back and said 'oh I see that this has to happen' and, and then has gone and sort of spoken to whoever she's identified who's been the nurse coordinating- and then almost negotiated herself when would it fit best as opposed to sort of standing back and observing. It's almost like she's moved through and just sort of engineered what is a very practical solution without sort of coming back and saying 'oh I'm not really sure what to do' (Participant 7 ). 
To this participant, in contrast, the traditional graduate may have 'really, really struggled with how they sort of fit into the, that team and the, the dynamics of how that works' (Participant 7) suggesting less initiative in some in the early stages of their graduate employment.

\section{A note of caution: Comfort zone; can't see the wood for the trees}

Yet some participants offered notes of caution. In the context of this analysis the 'comfort zone' was used to mean the accelerated graduates' reliance upon the subject and content of their first degree to assist them clinically. Some participants viewed this positively but others raised concerns. Examples in nursing literature suggest student nurses with previous experience in the business world could apply their management strategies to nursing but had difficulty mastering daily clinical routines (Miklancie and Davis 2005). Many of the physiotherapy participants believed their accelerated graduates' background to be Sports Science or similar subject matter. Some study participants thought it was 'evident' that the accelerated cohorts thought 'they only need to do the musculoskeletal kind of thing' regardless of which other clinical speciality they were currently working in (Participant 10). Hence some accelerated graduates were thought to 'have difficulty' in clinical areas such as respiratory care or care of the older person because:

a higher than proportion of Masters students seem to be from a sports background and appear to want, er, to see physiotherapy as purely musculoskeletal working in sport erm, ... and aren't as interested in the other aspect of physiotherapy and I think that's one of the reasons that they often have difficulty on placement on something like elderly care... so I would want to be sure that somebody had a good understanding of the, the job when applying (Participant 10).

It was thought that this musculoskeletal focus might have ramifications to their clinical work. Some accelerated graduates were said to miss significant clinical cues which, the study participants believed, the traditionally trained graduate would be more likely to have spotted. Within this analysis this shortcoming was described as being unable to 'see the wood for the trees'. It was thought that some of the accelerated graduates' clinical reasoning was too 
narrow minded making the transition to the neurological rehabilitation more difficult. However, even within the musculoskeletal field some were concerned that whilst the accelerated graduates 'just tend to be a lot more clued up' than traditional graduates they remained 'focussed on the specific problem rather than the whole scenario' (Participant 11). In doing so they would miss a more realistic treatment plan. This study participant believed that this was because:

the BSc students tend to be, look for things, in a maybe more holistic way and maybe more in a functional way rather than the Masters students tend to hone in on something specific. They'll know something that they've heard [from their previous course] and they'll hone in too quickly and won't think about, sort of, the more, the more broader aspects of it (Participant 11).

According to the study participants this approach appeared less likely with the traditionally trained students and graduates being less focused. As such they 'tend to look at the picture maybe a little bit more holistically' to problem-solve and so develop a more 'functional' approach (Participant 12).

\section{A note of caution: Over-confidence; loose cannon}

Whilst their interpersonal skills were praised by many the accelerated graduates' selfassurance was a cause for concern for some if they expressed their opinion 'too confidently'. According to one participant:

Politely, I think they're very confident in their own abilities and sometimes that's not always in the best interests of their work. Impolitely, I think sometimes MSc students can be quite cocky in their characters erm, not all, as, like I say, not everybody is but they certainly have got a very, a very self-assured in themselves. I see this in the students and in the, and in the juniors [new graduates]- when they start working. And like I say, they're confident (Participant 12).

This self-assurance was construed as 'over-confidence' by some participants who reported some accelerated graduates to have 'caused some friction' within the multi-disciplinary team (Participant 10). One stated that 'you can tread quite a fine line between getting [other team members'] backs up' (Participant 10). She went further:

'I have known a bit of an attitude in some [accelerated] graduates that they [consider themselves to be] are better. I've known of one who at least once 
a week commented 'I've got two degrees, you know'- and that can be a bit irritating' (Participant 10).

As such, some participants would prefer closer consultation with such graduates to suggest alternative clinical or managerial approaches for more effective team dynamics.

\section{DISCUSSION}

\section{Academic and clinical implications}

Pro's and con's of accelerated courses are well established in the literature. In this study physiotherapy participants described accelerated graduates as 'super-people'. Seifert (2004) suggested that academically successful, self-efficacious adult learners are more selfregulating and metacognitive. As such, the notion that accelerated graduates were 'superhuman' was intriguing from the start. Postgraduate expectations of academic proficiency are clearly identified and achievable by many (Quality Assurance Agency for Higher Education, 2008). Cangelosi (2007) and Scott (2003) argued that successful learning occurs when meaningful connections are made between previous experiences and new information. The senior physiotherapy clinicians acknowledged this. However, to them it was the timeframe and intensity of the shortened course that they focused upon and found incomprehensible. They admitted to having little understanding of the rationale for, and format of, accelerated courses. Yet by its nature accelerated course delivery is altered to reflect the intensive format of such courses. Educational literature for the allied health professions does not report nor question whether course content has been reduced to manage the accelerated format. However, one accelerated baccalaureate nursing programme in Massachusetts acknowledged that not all topics should be taught and stakeholders accepted 'the idea of eliminating content [that] they formerly viewed as vital to the course' (Caldwell et al, 2010, p295). To some extent these reflect the concern that accelerated courses sacrifice breadth 
and depth as noted in the fast-food analogy of the 'McDonalds of higher education' (Traub, 1997; Wlodkowski, 2003) and would be worthy of further study.

Participants spoke of the accelerated graduates' age, experience and maturity that benefited daily clinical work. They were said to 'hit the ground running'. This is reflected elsewhere (Bentley, 2006; Meyer et al., 2006). The analysis from this study suggested that accelerated physiotherapy graduates are well equipped in professional socialisation being the process by which individuals acquire the values, behaviours and attitudes necessary as their own to assume their professional role (Howkins and Ewens, 1999, p42). This contrasts with Cangelosi's (2007) qualitative study of accelerated nursing students in the US who were said to be confident academically but reported their sense of inadequacy in the clinical arena. Seifert (2004) believe that students who have successfully mastered previous knowledge and skills have self-confidence and personal judgement of their competence to undertake tasks. All participants commented upon the accelerated graduates' conscientious hard work and life experiences as being major contributions towards their academic and clinical success. It remains possible that some clinicians wished to sound complimentary towards accelerated graduates yet reverted to their assumption that they were good because they had managed to complete studies in a shortened time; not necessarily that they were good clinicians. This is particularly so as some participants questioned the breadth of the accelerated graduates knowledge, skills and interest across specialities. However, this may be unfair as one phenomenological inquiry of second-career baccalaureate nursing students acknowledged that 'not every nurse is capable of or interested in working in certain clinical specialty areas' (Kohn and Truglio-Londrigan, 2007, p398).

Second degree students have been described as excellent adult learners who excel in class, (American Association of Colleges of Nursing, 2009; Cangelosi and Whitt 2005; Wilkinson et al., 2004). From comparisons of traditional and accelerated US baccalaureate nursing graduates the latter achieved better academic outcome measures than their traditional 
counterparts (Bentley, 2006). In this study accelerated graduates were considered to be selfconfident yet there were examples of over-confidence and perceived arrogance. There was also a suggestion that some accelerated graduates over-stepped the mark. Elsewhere second degree students have been described as more challenging, demanding and questioning than traditional students (The American Association of Colleges of Nursing, 2009; Wilkinson et al., 2004). Cangelosi and Moss (2010, p139) noted that some accelerated nursing students were 'not afraid to question authority' to the extent that some could be 'intimidating' and were 'ready to buck the system'. It is possible that clinical supervisors might feel similar challenges from their students and graduates and would be worthy of further study.

Stewart et al. (2000) recommended that the terms 'confidence' and 'competence' should not be used synonymously. These issues are, again, worthy of further research and exploration as neither set of perceptions from the physiotherapy participants match the expectations of Honours and Masters level outcomes that relate to traditional and accelerated courses, respectively (Quality Assurance Agency for Higher Education, 2008). This suggests that careful selection of applicants to courses is required as well as adequate mechanisms for accelerated graduates to seek support.

\section{Limitations}

The sample size of this study was small and the majority of the data collection occurred in acute hospital settings. However large organisations were chosen to access sufficient participants that met the inclusion criteria to enable discussions for this first exploratory study with clinicians. It is recognised that as author and researcher there was insider knowledge of the profession and educational issues. Participants were encouraged to talk openly as if to a third person to minimise incidents of assuming prior knowledge. Audit trails and journals were used in the analytical stage to minimise risk of bias. It is also acknowledged that the nature of the conversations with clinicians tended to create direct comparisons between the 
two types of graduate. However, many participants spoke of each cohort in depth and could give examples to justify their beliefs.

\section{CONCLUSIONS}

Study participants valued accelerated graduates in their contribution to the workforce that was neither better, nor worse, than their traditionally trained counterparts but offered differing qualities to the service. Importantly, clinicians identified strengths and limitations from both cohorts. However, issues of clinical confidence and competence arose from the analysis for both cohorts. These presented themselves as varied success in self-motivation academically and clinically, problem-solving and team work. However, there were some concerns regarding over-reliance upon knowledge and skill from previous studies. These all had clinical and inter-personal ramifications as it required differing types of supervision amongst the two graduate types to consolidate and hone clinical skills and clinical reasoning skills.

Further research is required to explore clinician's perceptions. Nonetheless, there also remains a strong case for further promotion and discussion of the strengths of both traditional and accelerated pre-registration education to inform professions. Whilst the research relates directly to pre-registration physiotherapy education lessons can be learnt and transferred to accelerated education in other disciplines. 


\section{REFERENCES}

American Association of Colleges of Nursing. (2005). Accelerated Programs: The Fast-Track to Careers in Nursing. AACN Issue Bulletin. Retrieved from

http://www.aacn.nche.edu/Publications/issues/Aug02.htm

American Association of Colleges of Nursing. (2009). Accelerated Baccalaureate and Master's Degrees in Nursing. AACN Fact Sheet. Retrieved from http://www.aacn.nche.edu/Media/pdf/AccelProgs.pdf

Bentley, R., 2006. Comparison of traditional and accelerated baccalaureate nursing graduates. Nurse Educator 31 (2), 79-83.

Blythe, J. (2001). New fast track medical courses to start in UK. Student BMJ, 09, 305-356.

Caldwell, L. M., Tenofsky, L. M. and Nugent E. (2010). Academic and Clinical Immersion in an accelerated Nursing Program to Foster Learning in the Adult Student Nursing Education Perspectives 31 (5), 294-297.

Cangelosi, P. R. (2007). Voices of graduates from second-degree baccalaureate nursing programs. Journal of Professional Nursing 23 (2), 91-97.

Cangelosi, P. R. and M. M. Moss (2010). Voices of faculty of second-degree baccalaureate nursing students Journal of Nursing Education 49 (3), 137-142.

Cangelosi, P. R. and K. J. Whitt (2005). Accelerated nursing programs: what do we know Nursing Education Perspectives 26, 113-116.

Chartered Society of Physiotherapy (2003). Expectations of Master's level programmes within qualifying physiotherapy education. QA02 London, Chartered Society of Physiotherapy.

Chartered Society of Physiotherapy (2003). Master's level programmes within postqualifying physiotherapy education: CSP criteria and expectations. QA03. London, Chartered Society of Physiotherapy.

Craik, C., and Nappthine, C. (2001). Student's choice of occupational therapy as a second degree. British Journal of Occupational Therapy, 64 (9), 432-437.

Glasgow Caledonian University. (2004). MSc Rehabilitation Science. Definitive programmed document. April 2004. Glasgow.

Grounds, S. (1996). Accelerated degrees and their use in teacher education. Cambridge Journal of Education, 26 (2), 159-170.

Halkett, A., and McLafferty, E. (2006). Graduate entrants into nursing- are we meeting their needs? Nurse Education Today, 26 (2), 162- 168.

Howkins, E. J. and A. Ewens (1999). How students experience professional socialisation International Journal of Nursing Studies 36 (1), 41-49.

Husson, W. J., \& Kennedy, T. (2003). Developing and maintaining accelerated degree programs within traditional institutions. New directions for adult and continuing education, 97, 51-62. Retrieved from http://www3.interscience.wiley.com/cgi-bin/

Kasworm, C. E. (2003). From the adult student's perspective: accelerated degree programs. New directions for adult and continuing education, 97, 17-28. Retrieved from http://www3.interscience.wiley.com/cgi-bin/

Kohn, P. S. and M. Truglio-Londrigan (2007). Second-career baccalaureate nursing students: a lived experience Journal of Nursing Education 46 (9), 391-399.

Meyer, G. A., Hoover, K. G., \& Maposa, S. (2006). A profile of accelerated BSN graduates, 2004. Journal of Nursing Education 45 (8), 324-327.

Miklancie, M. and T. Davis (2005). The second-degree accelerated program as an innovative educational strategy: new century, new chapter, new challenge Nursing Education Perspectives 26 (5), 291-293.

Neill, M. A. (2011). Graduate-entry nursing students' experiences of an accelerated nursing degree - A literature review. Nurse Education in Practice 11 (2), 81-85.

Neill, M. (2012). Graduate-entry nursing students' journeys to registered nursing. Nurse Education in Practice 12, 89-94. 
Oermann, M. H., K. Poole-Dawkins, et al. (2010). Managers' perspectives of new graduates of accelerated nursing programs: how do they compare with other graduates? Journal of Continuing Education in Nursing 41 (9), 394-402.

Ouellet, L. L., Maclntosh, J., Ginbson, C. H., and Jefferson, S. (2008). Evaluation of selected outcomes of an accelerated degree program Nurse Education Today, 28 (2), 194201.

Quality Assurance Agency for Higher Education. (2008). Framework for Higher Education Qualifications in England, Wales and Northern Ireland. Retrieved from http://www.qaa.ac.uk/academicinfrastructure/FHEQ/EWNI08.pdfcrntwork/nqf/ewni/ew ni.htm

Ronning, W. M. (2009). Adult, Flexible Students' Approaches to Studying in Higher Education. Scandanavian Journal of Educational Research 53 (5), 447-460.

Scott, P. A. (2003). Attributes of high-quality intensive courses. New directions for adult and continuing education, 97, 29-38. Retrieved from http://www3.interscience.wiley.com/cgi-bin/

Seifert, T. (2004). Understanding student motivation. Educational Research, 46 (2), $137-$ 149.

Seldomridge, L. A. and M. C. DiBartolo (2005). A profile of accelerated second bachelor's Degree nursing students Nurse educator 2, 65-68.

Smith, J. A., Flowers, P., \& Larkin, M. (2009). Interpretative Phenomenological Analysis: theory, method and research. London: Sage Publications.

Stewart, J., O'Halloran, C., Barton, J. R., Singleton, S. J., Harrigan, P., \& Spencer, J. (2000). Clarifying the concepts of confidence and competence to produce appropriate selfevaluation measurement scales. Medical Education 34, 903-909.

Traub, J. (1997). Drive-thru U. New Yorker, Oct 1997 (20-27), 114-123.

Wilcock, A. (2002). Occupation for health: Journey from prescription to self health. Volume 2. London: British College of Occupational Therapists.

Wilkinson, T. J., Wells, J. E., \& Bushnell, J. A. (2004). Are differences between graduates and undergraduates in a medical course due to age or prior degree? Medical Education 38, 1141-1146.

Wlodkowski, R. J. (2003). Accelerated learning in colleges and universities. New directions for adult and continuing education, 97, 5-15. Retrieved from http://www3.interscience.wiley.com/cgi-bin/

Wu, \& Connelly. (1992). Profile of non-nurse college graduates enrolled in Accelerated Baccalaureate Nursing Programs. Journal of Professional Nursing 8 (1), 35-40.

Youssef, F. A., \& Goodrich, N. (1996). Accelerated versus traditional nursing students: a comparison of stress, critical thinking ability and performance. International Journal of Nursing Studies 33 (1), 76-82. 